\title{
MJMR STRUCTURED ASSESSMENT, EVALUATION AND MONITORING PARAMETERS: CRITICAL CORRELATES TO THE PERCEIVED EFFECTIVENESS OF SCHOOL-BASED DEWORMING PROGRAMS
}

\author{
Randy lan F. Gallego*, Amalhyatt M. Abdullah \\ College of Health Sciences, Mindanao State University, Main Campus, Marawi City, Philippines \\ *Corresponding Author's Email: randyian.gallego@msumain.edu.ph
}

\begin{abstract}
Background: Soil-transmitted helminths are the most common cause of childhood parasitic infection particularly in developing countries. Government efforts are geared towards addressing this health concern especially among school-aged children who are most vulnerable to intestinal infections secondary to environmental exposure from play and recreation. This study examines the determinants of effectiveness of the national deworming program initiated by the Department of Health in Marawi City, Philippines. Methods: The study used descriptive-correlational research design involving 50 parents/guardians of children who were recipients of the national deworming program. Validity and reliability-tested questionnaires were used as instrument. The data obtained was analyzed using frequency and percentage distribution, weighted mean and Chi-square correlation technique. Results: When tested at 0.05 level of significance, the chi-square values obtained were $\left(x^{2}=108.494\right)$ and $\left(x^{2}=42.957\right)$ at $p$-value $=0.000$, revealing that assessment, evaluation and monitoring of the recipients before and after deworming interventions have a significant association to the perceived effectiveness of the program. Conclusion: The present national school deworming drive can be improved further by creating clear-cut protocols and procedures to assess parameters that would measure assessment findings, evaluation and monitoring of children vis-à-vis effects of anti-helminthic drugs taken.
\end{abstract}

\section{Keywords: Assessment; Evaluation and Monitoring; School-based Deworming Program; Philippines}

\section{INTRODUCTION}

Deworming, also referred to as drenching, is the process of eliminating intestinal helminths that are most commonly contracted through the consumption of food and water sources that are contaminated by parasitic agents. Children are placed at a higher risk of intestinal colonization of worms due to their natural exposure to pathogenic agents resulting from constantly being exposed to field-based play and the reflexive impulse to put everything that is grabbed directly to the mouth. In terms of prevalence, species such as roundworms, whipworms, and hookworms are known to be the most common soil-transmitted worms that are most usually associated with malnutrition and disease in children.

The means by which these intestinal parasites are transmitted into the body are through the ingestion of eggs that are found in contaminated soils, food products, water supply, and even through larvae penetration of the skin after having been in contact with a known contaminant. Generally, the transmission and acquisition of helminthic worms can be attributed largely to poor living conditions and improper sanitation practices which are most incidentally present in areas that are heavily affected by poverty. Consequently, studies show that conditions based on poor hygiene-sanitation standards and lessened protective skin-barrier resources are strongly associated with the development of worm parasitism in humans (Bethony et al., 2006).

In general, literatures show that presence of worm infestation is contributory to the development of childhood sickness, but rarely causes death. The burden associated with morbidity can be linked to the economic costs of worm treatment and the consequent hospitalization from its complications. For instance, infection from worms can cause changes in children's nutritional status. Worms in the intestinal cavity may feed on the host's colonic layers causing interference in the capacity of the alimentary tract to absorb nutrients and minerals (Hall et al., 2008). These changes, if not corrected, can lead to the development of anemia and/or micronutrient deficiencies in children causing impaired growth and physical stunting. Other complications 
include delayed intellectual and cognitive development, diminished functional capacity, generalized weakness and fatiguability, and poor academic performance (Cairncross and Valdmanis, 2006; Olds, 2013). Children who are seen to have decreased attendance in school during their formative years in education are more likely to experience major sequelae over the course of their adult lives. Absenteeism is associated with impediments in their capacity to thrive in the labor force and market outcomes thus perpetuating the cycles of poverty and health equity gaps (Sianesi and Van Reenen, 2003).

Deworming is generally characterized as the administration of anti-helminthic medications to reduce and eliminate the presence of intestinal parasites along with the associated risks and complications it carry (WHO-Strategy Development and Monitoring for Parasitic Diseases and Vector Control Team, 2005). Anti-helminthic drugs are given for public use and consumption after having received their clearance and approval as safe and effective for children. Years of consolidated knowledge and research findings on the effectiveness of anti-helminthic specifically mebendazole and albendazole have been instrumental and are utilized primarily in the global campaign for the eradication of soil-transmitted helminthiasis (STH) since the 1990's. The World Health Organization (WHO) sets its recommendation to curb childhood morbidity from parasitism through the regular administration of a single dose of either albendazole (400 mg) or mebendazole $(500 \mathrm{mg}$ ) to children who are at greater risk of contracting intestinal infestation from helminths (WHO, 2012b). Consequently, study findings concur that regular deworming schedules for children are impactful in achieving good health and nutrition between the ages six (6) to twelve (12) years (WHO \& World Bank, 2003). These developments are seen to positively increase school enrolment figures and attendance rate, reduce the incidence of subject failure and repeating of subjects, and higher educational advancement. However, the same study also reports of certain populations that are at a disadvantage: the girls and those coming from impoverished social backgrounds. They are noted to suffer most from the ill effects of malnutrition and poor health. Hence, they are believed to earn the most gain with the implementation of deworming programs (WHO \& World Bank, 2003).

In the Philippines, the Department of Health (DOH) has been making a headway in its nationwide campaign to eliminate intestinal parasitism in children. The agency, in tight collaboration and partnership with academic institutions and the local government units (LGUs), are distributing anti-helminthic drugs during the National Deworming Month (NDM). This biannual program is held during the months of January and July. Presently, there are two major subcomponent initiatives under NDM: the first one is school-based and the other is community-driven. The National School-Deworming Month (NSDM) is considered as a massive effort of the $\mathrm{DOH}$ to simultaneously conduct deworming initiatives and cover as much school-aged children in public institutions of learning. In January of 2018, the campaign was able to deworm as many as 7,919,273 pre-school children (out of 10,612,738) accounting for about $74.60 \%$ coverage rate. Among school-aged children, the campaign was able to launch an $84.50 \%$ deworming coverage. This is translated in figure as a total of 17,060,163 dewormed children (out of 20,194,252) who were officially enrolled in that particular school year (DOH, 2018).

In the local context, the MOH-Bangsamoro Autonomous Region in Muslim Mindanao (BARMM) in 2016 has administered deworming medicines to a total of 303,523 children aged 5 to 12 years. This made up for about $52.64 \%$ of the total number of children enrolled in public elementary schools in the region $(\mathrm{MOH}-$ BARMM, 2016). Such statistics reveal that only half of the target population has received the appropriate antiparasitic therapy in the locality where this study was conducted. There remained to be a significant number of children who have not availed of the government's deworming initiative. This disparity can be attributed to certain factors which have to be properly identified to improve the efficiency and effectiveness of the government's deworming campaign and promote good health outcomes for children.

With the increasing recognition that soil-transmitted helminths have a detrimental impact on a much larger scale to the populations at risk, and that growing children may suffer disproportionally from the potential morbid sequelae carried by the risks of intestinal colonization of parasites (Olds, 2013), it is important to identify existing factors that are influencing the degree to which the deworming program has been implemented in the Bangsamoro Region, particularly in its capital Marawi City. This study aimed to determine the parents' 
perception of the Department of Health's deworming programs particularly in the assessment, and evaluation and monitoring strategies pre- and post-deworming administration. It also explored on the respondents' perceived appraisal of the effectiveness of the deworming campaign in terms of their children's overall health and academic disposition.

\section{METHODOLOGY}

The data for this study was generated from a crosssectional, self-administered survey of 50 purposively selected parents and/or guardians of school-aged children who were recipients of the school-based deworming program in two (2) target schools in Marawi City: Basak Elementary School and Sultan Conding Elementary School. Parents and guardians were selected to respond to the survey instrument because they were the ones who would primarily notice the changes in their children's health status.

A descriptive-correlational research design was selected to fulfill the aim of the study. It is descriptive in purpose, gathering salient personal and socio-economic data to describe the variables: respondents' profile, extent of access to the deworming services and the respondents' perception of the effectiveness of the deworming outcomes to their children who were enrolled in the antihelminthic program of the City Health Office. Results were then tested, described, and treated with a correlational analysis.

In this study construct validity of the tool was achieved by pilot testing, validation by experts and using literature review as a basis for questionnaire development. Reliability was also achieved by obtaining Cronbach's alpha (0.85) value for the Likert-type responses.

Ethical review was then sought from the MSU-College of Health Sciences Research Committee and was given clearance (per CHS-REC Office Order No. 9-s. of 2018) to proceed with the actual data collection. Informed consents were stapled on each research questionnaire where respondents were explained of their rights and assured of their anonymity and privacy.

The content of each scale was analyzed, categorized and then coded by the researcher. The respondents' responses were treated using the Statistical Package for Social Science (SPSS) version 20. Statistical formula using descriptive statistics were utilized for quantitative variables that needed to be presented utilizing frequencies, percentages, means, and standard deviations. Chi square analysis was used in determining relationships between the identified variables. Statistical significance was considered at $p$-value $\leq .05$ with a critical value of 2.000 .

\section{RESULTS AND DISCUSSION}

This section presents the data collected in tabular form. Similarly, tables and discussions are presented according to the following flow: frequency and percentage distribution of the socio-demographic profile of the respondents, descriptive statistics of the extent of access to the deworming services provided by the BARMM City Health Office, and the descriptive statistics of the perception on the effectiveness of deworming program. Finally, correlation results are presented thereafter.

Table 1: Frequency Distribution of the Studied Sample According to their Socio-demographic Profile Characteristics (No. $=50)$

\begin{tabular}{|c|c|c|c|}
\hline Variables & & No. & $\%$ \\
\hline \multirow{4}{*}{ Age Group } & $12-20$ & 3 & 6 \\
\hline & $21-30$ & 17 & 34 \\
\hline & $31-60$ & 29 & 60 \\
\hline & 61 and up & 0 & 0 \\
\hline \multirow[t]{2}{*}{ Gender } & Male & 9 & 18 \\
\hline & Female & 41 & 82 \\
\hline \multirow[t]{5}{*}{ Civil Status } & Single & 7 & 14 \\
\hline & Married & 38 & 76 \\
\hline & Widowed & 3 & 6 \\
\hline & Divorced & 1 & 2 \\
\hline & Separated & 1 & 2 \\
\hline \multirow[t]{4}{*}{$\begin{array}{l}\text { Monthly } \\
\text { Income }\end{array}$} & 0,001 Php - 6,000 Php & 33 & 66 \\
\hline & $6,001 \mathrm{Php}-10,000 \mathrm{Php}$ & 13 & 26 \\
\hline & $\begin{array}{c}10,001 \mathrm{Php}-15,000 \\
\text { Php }\end{array}$ & 4 & 8 \\
\hline & 15,001 Php and up & 0 & 0 \\
\hline Educational & Elementary Level & 10 & 20 \\
\hline \multirow[t]{6}{*}{ Attainment } & Elementary Graduate & 2 & 4 \\
\hline & High School Level & 11 & 22 \\
\hline & High School Graduate & 5 & 10 \\
\hline & College Level & 17 & 34 \\
\hline & College Graduate & 4 & 8 \\
\hline & Others & 1 & 2 \\
\hline Employment & Employed & 46 & 92 \\
\hline Status & Unemployed & 4 & 8 \\
\hline
\end{tabular}


Table 1 shows the socio-demographic data of the studied sample. Female respondents, who comprised forty-one (41) of the sample population, representing $82.00 \%$ of the population, outnumbered the male respondents. This finding is to be expected since in the Filipino context, women are expected to be the one to assume the more domesticated function and are usually home-based. Mothers find staying at home with their kids a truly rewarding role. This is also seen as the primary reason why some mothers would have to quit their jobs after giving birth; never to return to the workforce. Essentially, infants and very young children rely heavily on their parents as well as their other caregivers for the provision of the nurturing and rearing responsibilities: to protect, care, and attend to their needs as well as in charting a trajectory that nourishes their overall well-being (Gadsden et al., 2016).

Consequently, most of the respondents have an age bracket of 31 - 60 years. Majority were married $(76.00 \%)$ and some have received college level of education $(34.00 \%)$. Furthermore, the biggest portion of the respondents are unemployed $(92.00 \%)$. Many of them $(66.00 \%)$ have a monthly income of below 6,000 Php. Relatively, studies show that low income households have higher risk of developing infections (WHO-Strategy Development and Monitoring for Parasitic Diseases and Vector Control Team, 2005). Majority of these developing infections like worm infestations are present in poverty-stricken areas seen in low-income tropical and sub-tropical countries. These conditions are particularly present in impoverished communities where people are living below middle income level. There is an increased likelihood of infestation in areas where there is no proper waste disposal system, decreased access to potable sources of water, and where unhygienic and unsanitary living conditions were highly evident. Consistently, because of poverty, a survey by the Social Weather Station in 2006 shows that majority of Filipinos specifically those that are coming from low income households only decides to seek treatment in government hospitals once the sick family member is already in serious condition prompting urgent medical confinement (DOH, 2012). Therefore, government efforts to combat prevalence of communicable diseases in general need not only be directed on the provision of medicines to existing acute and chronic pathologies; they have to be more encompassing to include availability of better social welfare programs, and strengthened illness-preventive and healthpromotive approaches. To fully address long-standing societal issues in the country, social progress and inclusive fiscal development need to be felt down to the level of the common, ordinary people.

Table 2: Descriptive Rating on the Access to Deworming Services in Terms of Assessment Prior to Administration to Children-Recipients

\begin{tabular}{|c|c|c|}
\hline STATEMENTS & Mean & Interpretation \\
\hline $\begin{array}{l}\text { 1. My child's deworming medication was checked } \\
\text { and verified if not yet expired. }\end{array}$ & 2.26 & Seldom \\
\hline $\begin{array}{l}\text { 2. My child has been dewormed in school where } \\
\text { medical supplies are assessed for availability. }\end{array}$ & 1.40 & Never \\
\hline $\begin{array}{l}\text { 3. My child was properly weighed prior to their } \\
\text { deworming. }\end{array}$ & 1.66 & Never \\
\hline $\begin{array}{l}\text { 4. My child was assessed for deworming needs prior } \\
\text { to deworming. }\end{array}$ & 1.96 & Seldom \\
\hline 5. My child was observed for proper feeding pattern. & 1.98 & Seldom \\
\hline $\begin{array}{l}\text { 6. My child was observed for signs of parasitic } \\
\text { infestations. }\end{array}$ & 1.78 & Seldom \\
\hline Over-all Mean & 1.8400 & Seldom \\
\hline
\end{tabular}

1.00-1.74= Never $1.75-2.49=$ Seldom $2.50-3.24=$ Often $3.25-4.00=$ Always

Tables 2 and 3, on the other hand, reveals that in terms of the Access to the Deworming Services, the respondents believe that their children were only seldomly assessed, evaluated and monitored prior and after the deworming program.

Table 3. Descriptive Rating on the Access to Deworming Services in Terms of Evaluation and Monitoring After the Administration to Children-Recipients

\begin{tabular}{|l|c|c|}
\hline STATEMENTS & Mean & Interpretation \\
\hline $\begin{array}{l}\text { 1. I was advised go to the CHO twice a year for my } \\
\text { child deworming schedule. }\end{array}$ & 1.78 & Seldom \\
\hline $\begin{array}{l}\text { 2. I have been asked by the CHO about the effects of } \\
\text { the deworming medication to my child's body and } \\
\text { health weeks after the intake of drug. }\end{array}$ & 1.84 & Seldom \\
\hline $\begin{array}{l}\text { 3. My child was observed for side and adverse effects } \\
\text { of the deworming medication. }\end{array}$ & 2.04 & Seldom \\
\hline $\begin{array}{l}\text { 4. My child was regularly followed up after } \\
\text { deworming. }\end{array}$ & 2.00 & Seldom \\
\hline $\begin{array}{l}\text { 5. My child was observed for therapeutic effects of the } \\
\text { drug after intake. }\end{array}$ & 2.42 & Seldom \\
\hline Over-all Mean & $\mathbf{2 . 0 1 6 0}$ & Seldom \\
\hline
\end{tabular}

1.00-1.74= Never $1.75-2.49=$ Seldom $2.50-3.24=$ Often $3.25-4.00=$ Always

Previous studies show that anti-helminthic drugs are 
generally safe and therefore are recommended for children including those without prior history of worm infestation. Hence, diagnostic examination and physical assessment are not a pre-requisites to helminthic treatment. This factor may be accounted as the reason why most assessment procedures are not routinely included in the deworming program. Even then, the WHO actively asserts the importance of having all children to go through the periodic treatment of anthelminthic (deworming) medications particularly those who are residing in localities where worm infection is endemic. The WHO, however, no longer recommends for the individual screening of every child since the cost of screening is tenfold more expensive than that of the actual treatment itself (Taylor-Robinson et al., 2015).

Similarly, the World Health Organization, in 2005, still contends that the assessment and monitoring of the efficacy of anthelminthic drugs need to be regularly performed and must follow the prescribed standards especially in areas where they are commonly used so as to warn their target recipients of the various potential treatment risks and failures. Although deworming tablets given to children are for free, safe, effective, and beneficial, health officers are instructed to still come up with a master list of all children who have availed of the program. They are also directed to conduct assessment beforehand to make sure that the child is fit for deworming. This consultation is part of the safety nets that will ensure protection of the child from the possible side effects especially after taking the tablet. Symptoms, which when experienced by children will necessitate further clinical monitoring, include headache, abdominal pain and vomiting. It is therefore recommended that during school-based deworming programs, school personnel and health officials need to work closely together to determine which treatment day is the most appropriate for the distribution of deworming medications and the other health and nutrition services package. Health personnel should be made aware of any antihelminthic drug distribution schedule by teachers. They should also be ready to provide support and supervision in the event where unwanted side effects are observed and assessed (Savioli et al., 2004) .
Table 4. Mean and Descriptive Rating of the Effectiveness of Deworming Program Provided by the BARMM-CHO as perceived by the Respondents

\begin{tabular}{|c|c|c|}
\hline After my Child was Dewormed & Mean & Interpretation \\
\hline 1. My child's appetite improved. & 3.40 & Strongly Agree \\
\hline 2. My child is not easily getting sick. & 2.76 & Agree \\
\hline $\begin{array}{l}\text { 3. I can see that my child gained weight } \\
\text { appropriate with his/her age. }\end{array}$ & 2.78 & Agree \\
\hline $\begin{array}{l}\text { 4. My child improves his concentration } \\
\text { especially when studying. }\end{array}$ & 3.10 & Agree \\
\hline $\begin{array}{l}\text { 5. I can see that my child improved } \\
\text { his/her academic grades. }\end{array}$ & 3.06 & Agree \\
\hline $\begin{array}{l}6 . \text { I can see that my child is now } \\
\text { becoming tall appropriate with his/her } \\
\text { age. }\end{array}$ & 3.06 & Agree \\
\hline $\begin{array}{l}\text { 7. My child attends to his/her class } \\
\text { regularly compare before when he was } \\
\text { not yet dewormed. }\end{array}$ & 3.62 & Strongly Agree \\
\hline 8. My child learns better than before. & 3.12 & Agree \\
\hline $\begin{array}{l}\text { 9. My child becomes active and more } \\
\text { productive in school. }\end{array}$ & 3.42 & Strongly Agree \\
\hline $\begin{array}{l}\text { 10. My child has decreased episodes of } \\
\text { LBM. }\end{array}$ & 2.66 & Agree \\
\hline $\begin{array}{l}\text { 11. My child can now focus on his } \\
\text { homework from school properly. }\end{array}$ & 3.22 & Agree \\
\hline 12. My child is no longer always drowsy. & 3.02 & Agree \\
\hline 13. My child is no longer under-nourish. & 3.20 & Agree \\
\hline $\begin{array}{l}\text { 14. My child has seldom experience } \\
\text { abdominal pain. }\end{array}$ & 2.62 & Agree \\
\hline $\begin{array}{l}\text { 15. Mental development of my child } \\
\text { seems to be consistent with his age. }\end{array}$ & 3.20 & Agree \\
\hline Over-all Mean & $\mathbf{3 . 0 8 2 7}$ & Agree \\
\hline
\end{tabular}

Consequently, Table 4 shows the effectiveness of Deworming Program provided by the BARMM-CHO as perceived by the respondents. In general, the parents and guardians of the recipients of the anti-helminthic medicines agreed that there was improvement in the health status of their children after having been dewormed. Mostly, children were observed to be more active and productive in school, attended classes more regularly, and had improvement in their appetite.

The WHO (2005) reported that deworming undoubtedly makes a significantly positive contribution to the education of children, and ultimately, to the nation's development. This is particularly highlighted in the same report finding which reveals that children who are affected with the debilitating complications of parasitism spend fewer days of attendance in school when compared to those 
who relatively show no worm-infection symptoms. Similarly, children with serious whipworm infestation were seen to miss twice as many school days than those not affected. This result has been demonstrated convincingly in Jamaica and in Kenya showing that deworming programs increased school attendance. Children who have received treatment were seen to gain much more from their increased time in school, not only because they are free from illness but also because their cognitive performance improved and that they learn significantly faster. Tests have shown that a child's short-term memory, long-term memory, executive function, language, problem solving, and attention respond positively to deworming (WHO, 2005).

The rationale for the effects of deworming programs on population development depends on the assumption that they improve nutrition, hemoglobin, and cognition. As a result of these benefits, children are thought to have increased physical well-being, with improved intellect, and are better able to attend school. As a result, curricular competence and performance is enhanced. Overtime, this benefits society as a whole, and reduces the incidence of poverty (WHO, 2005; WHO, 2012a).

Table 5. Relationship Between the Access to Deworming Services and the Effectiveness of the Deworming Program as Perceived by the Respondents

\begin{tabular}{|l|c|c|c|c|c|}
\hline $\begin{array}{l}\text { Access to Health } \\
\text { Services }\end{array}$ & $\begin{array}{c}\text { Chi-Square } \\
\text { Value }\end{array}$ & $\begin{array}{c}\boldsymbol{P} \text { - } \\
\text { Value }\end{array}$ & Decision & Conclusion \\
\cline { 1 - 4 } $\begin{array}{l}\text { a.) Assessment Prior to } \\
\text { the Program }\end{array}$ & $\begin{array}{c}\text { Effectiveness } \\
\text { of the } \\
\text { Program }\end{array}$ & 108.494 & 0.000 & Reject $H_{0}$ & $\begin{array}{c}\text { Highly } \\
\text { Significant }\end{array}$ \\
\cline { 3 - 6 } $\begin{array}{l}\text { b.) Evaluation and } \\
\text { monitoring to the } \\
\text { Recipients }\end{array}$ & 42.957 & 0.000 & Reject $H_{0}$ & $\begin{array}{c}\text { Highly } \\
\text { Significant }\end{array}$ \\
\hline
\end{tabular}

Table 5 illustrates the relationship between the access to deworming services and the effectiveness of the deworming program as perceived by the respondents. The result shows that there is a significant relationship between the assessment prior to the program $\left(x^{2}=108.494\right)$; the evaluation and monitoring after administration of deworming medicines $\left(x^{2}=42.957\right)$ and the perceived effectiveness of the deworming program at $p$-value $=0.000$, and $>\alpha=0.05$. The chisquare test for independence was used to test the hypothesis of association between the variables. It can be inferred that the presence of standardized tools to assess school-aged children as well as structured monitoring and evaluation protocols before - and after deworming interventions can have an impact on the perceived effectiveness and efficiency of the program.
In the data collection phase, most of the respondents verbalized that their children did not receive formal physical examination prior to the giving of the deworming medications. They also reported minimal monitoring and feedback from the City Health Office vis-à-vis response of the child to the post-medication administration.

It was stated in the WHO-World Bank Joint Statement: School Deworming at a Glance (2003) that all deworming activities conducted by national health agencies must include a routine monitoring strategy that reflects the recording of basic process indicators: the number (or percentage) of children treated and the quantity of drugs used. These indicators serve as the basis in the development of appropriate deworming plans and aid in reducing the incidence of inappropriate drug use. In cases where a more detailed evaluation is needed, the program impact may be determined using an epidemiological survey. Thus, the need for evaluation and monitoring is a must in treating and providing deworming program for the recipients of the medications.

Similarly, this issue seemed to be acknowledged by a WHO report noting the considerable importance of having to monitor and evaluate the impact of deworming programs to the health of the people and its subsequent contribution to the nation especially for program managers and policy-makers so they can assess whether all deworming objectives are being met and, if necessary, correct the implementation strategy if there are flaws or setbacks in the implementation process (WHO, 2012b). However, national programs often lack the resources needed to conduct such evaluation activities efficiently. In view of this challenge, program managers and all concerned national officials engaged in the planning, implementation, and monitoring and evaluation of activities in STH control components, must be able to convene regularly to develop enhanced capacity needed to pursue deworming-related competencies. It is also equally important to support activities that would result in the formulation of operational tools, guidelines, and operations manual. These shall help set the flow and direction to be followed for sectors that are directly involved in the implementation of national programs in the control of intestinal parasitism. Lastly, there should be guidance and more aggressive strategies in the remapping and reaching out of more children to take part in the national deworming campaign. 


\section{CONCLUSION}

The campaign against intestinal parasitic infestations, in general, is seen to be well supported logistically from the national to local levels in the Philippines. Stakeholders involved are observed to be cooperative in making sure that the program is delivered safely and appropriately despite certain limitations in the implementation. The findings of this study, therefore, can be utilized in the reinforcement of some routine aspects and procedures of the deworming drive. In the case of assessment and evaluation, policies may be identified to put mechanisms to improve the monitoring of children's status all throughout the course of the anti-helminthic therapy such as the institutionalization of Adverse Event Protocols or Deworming Emergency Response System. Higher compliance and better health outcomes can be expected once these safeguards are established.

\section{Conflict of Interest}

The authors declare that the study was conducted in the absence of any commercial or financial relationships that could be construed as a potential conflict of interest.

\section{ACKNOWLEDGMENTS}

An endeavor of this kind takes final shape only through the collaborative effort of many minds and hands. The authors are very much in the debt of those people who have given generously of their time, knowledge, and expertise to see this work through to its completion. To them, I would like to express my profound gratitude and sincere appreciation: the respondents, the school administrators who allowed conduct of the study in their institutions, the technical panel: Ms. Ma. Theresa Namalata, Ms. Shiennah Lunag-Jamesula, the ethical review committee, the statistician.

\section{REFERENCES}

Bethony, J., Brooker, S., Albonico, M., Geiger, S.M., Loukas, A., Diemert, D. \& Hotez, P.J. (2006). Soiltransmitted helminth infections: ascariasis, trichuriasis, and hookworm. The Lancet, 367(9521), pp.1521-1532.

Cairncross, S. \& Valdmanis, V.(2006). 'Disease Control in Developing Countries: Chapter 41 Water Supply, Sanitation and Hygiene Promotion', Disease Control in Developing Countries.

Department of Health (2018).Conducts National Deworming Month to Reinforce Prevention and Control of Soil-transmitted Helminths. Retrieved from: https://www.doh.gov.ph/node/10545 on February 12,2019
Department of Health (2012). National Objectives for Health 2011 - 2016, Health Sector Reform Agenda Monograph No. 12.

Gadsden, V. L., Ford, M. \& Breiner, H.(2016). Parenting matters: Supporting parents of children ages 0-8, Parenting Matters: Supporting Parents of Children Ages 0-8. doi: 10.17226/21868.

Hall, A., Hewitt, G., Tuffrey, V. \& De Silva, N. (2008). A review and meta-analysis of the impact of intestinal worms on child growth and nutrition. Maternal \& Child Nutrition, 4, pp.118-236.

Ministry of Health (2016). Bangsamoro Autonomous Region in Muslim Mindanao. Retrieved from: https://armm.doh.gov.ph/index.php/en/2uncategorised/181-armm-deworms-thousands-ofschool-children on February 24, 2019

Olds, G. R. (2013). 'Deworming the world.', Transactions of the American Clinical and Climatological Association.

Savioli, L., Albonico, M., Engels, D. \& Montresor, A. (2004). Progress in the prevention and control of schistosomiasis and soil-transmitted helminthiasis. Parasitology International, 53(2), 103-113.

Sianesi, B. \& Van Reenen, J.(2003). 'The returns to education: Macroeconomics', Journal of Economic Surveys. doi: 10.1111/1467-6419.00192.

Taylor-Robinson, D. C., Maayan, N., Soares-Weiser, K., Donegan, S. \& Garner, P. (2012). Deworming drugs for soil-transmitted intestinal worms in children: effects on nutritional indicators, haemoglobin and school performance. Cochrane Database of Systematic Reviews, (11).

World Health Organization. (2005). Strategy Development and Monitoring for Parasitic Diseases and Vector Control Team 'Deworming : the Millennium Development Goals', Geneva, Switzerland.

World Health Organization. (2012) .Helminth control in school-age children - Second Edition, World Health Organization.

World Health Organization (2012). 'Research priorities for helminth infections: technical report of the TDR disease reference group on helminth infections', World Health Organization Technical Report Series. doi: 10.1016/B0-12-386860-2/00348-8.

World Health Organization \& World Bank (2003). 'WHO-World Bank Joint Statement: School Deworming at a glance', Tropical Medicine. 